\title{
The Adoption of e-Learning 2.0 in Higher Education by Teachers and Students: An Investigation Using Mixed Methods Approach
}

\author{
Mohd Hafiz Zakaria, Jason Watson, and Sylvia L. Edwards
}

\begin{abstract}
This paper describes an approach to investigate the adoption of Web 2.0 in the classroom using a mixed methods study. By using a combination of qualitative or quantitative data collection and analysis techniques, we attempt to synergize the results and provide a more valid understanding of Web 2.0 adoption for learning by both teachers and students. This approach is expected to yield a better holistic view on the adoption issues associated with the elearning 2.0 concept in current higher education as opposed to single method studies done previously. This paper also presents some early findings of e-learning 2.0 adoption using this research method.
\end{abstract}

Index Termss-E-learning 2.0, adoption, teachers, students, higher education, mixed methods.

\section{INTRODUCTION}

As research in e-learning tools continues, there is a strand of studies being done specific on Web 2.0 and its potential to improve teaching and learning. Put briefly, these translate into a reinterpretation of current e-learning terminology (or known e-learning 1.0) to become e-learning 2.0. The use of " 2.0 " notion in this context is to signify the integration of online social collaboration afforded by social software within the Web 2.0 environment onto existing e-learning application [1]. Unlike the 'old web', the advent of online social media mediated by a range of Web 2.0 tools has revolutionized the way people exchange content and share knowledge. From an educational angle; this has triggered the social learning and active participation advocated by the constructivist learning theorist. However, the e-learning 2.0 concept itself is still fuzzy, buried under the complexities of technology, implementation design, existing technology and others. Yet, current literature indicates a diverse adoption of Web 2.0 applications by teachers and students is happening at a staggering speed with mixed results. The authors propose that a more rigorous research approach needs to be conducted to fully investigate Web 2.0 adoption and to enhance the learning experience especially in higher

Manuscript received October 9, 2011; revised March 5, 2012. M. H Zakaria thanks Universiti Teknikal Malaysia Melaka (UTeM) for granting him sponsorship to pursue his doctoral research at Queensland University of Technology.

M. H. Zakaria is now with the Department of Interactive Media, Universiti Teknikal Malaysia Melaka, Malaysia (email: hafiz@utem.edu.my).

J. A. Watson is with Science and Engineering Faculty, Queensland University of Technology, Australia (email: ja.watson@qut.edu.au).

S. L. Edwards is an adjunct professor at Science and Engineering Faculty, Queensland University of Technology, Australia. (email: s.edwards@qut.edu.au). education context.

\section{BACKGROUND}

Ever since Web 2.0 concept was re-enacted half a decade ago, it has provided teachers with new learning potentials and opportunities to support a variety of learning activities in different kinds of learning settings. Studies have been conducted to explore the adoption of Web 2.0 tools in education. A range of qualitative and quantitative research approaches have been used to study issues related to the implementation of Web 2.0 in education through experimental works, student observation, surveys distribution as well as conducting focus group or interviews. In general, surveys and interviews have been the two most popular techniques adopted to investigate Web 2.0 adoption in education area. A few key studies in this area have conducted investigations using various research methods:

- Higher education response to Web 2.0 emergent in learning environment through webinar discussions [2], survey analysis [3] and literature review [4];

- Student's learning preferences and expectations using survey and follow up interviews [5], [6];

- Students ownership and use of current ICT technologies using surveys and interviews [7]- [9];

- The integration of Web 2.0 tools in teaching and learning [10]; and

- Web 2.0 incorporation strategies and effectiveness in learning activities using empirical analysis [11].

The outcomes of these studies have reported insights of Web 2.0 integrations in education, the kinds of reactions observed from students; as well as examples of teachers' elearning 2.0 implementation ideas. While much of the research being done is in the adoption of Web 2.0 tools in teaching and learning, scholars have agreed that there is a need for more rigorous studies to expand our understanding in this field [4], [12], [13]. They implied that the amount of research in this area is still lacking, potentially due to the intricacy and fast changing nature of web services. Overseeing the complexity of the e-learning 2.0 concept, mixed methods approach is deemed to provide better snapshots of present scenario since the subjects were addressed from different perspectives or paradigms allowing us to gain a holistic perspective of the situation.

\section{CONCEPTUAL FRAMEWORK}

This section will explain a framework that describes the convolution of e-learning 2.0 concept and highlights how mixed methods approach can be used in our study to address 
adoptions issues from teachers and students. Currently, $21^{\text {st }}$ century learning is centered on the importance of collaboration and constructive learning activities. Learning in this era is fundamentally collaborative in nature; and social networks appear around common learning interests by current students contributing in the ramification of digital age learning. The concept is consisted within a multifaceted layers, and spans beyond the needs to understand only the teachers or the students. Rather, the apprehension of the surrounding areas is needed in order to grasp the full body of e-learning 2.0 idea.

\section{A. Conceptual e-Learning 2.0 Model}

The decision to adopt mixed methods is contributed by the complexities of the e-learning 2.0 scenario. Figure 1 illustrates a conceptual diagram of an implementation of Web 2.0 tools in a typical higher education learning setting. It portrays an example of a teaching and learning practice through a sequence of learning activities with some incorporation of Web 2.0 applications. In some instances, the learning activities can also be mediated by existing Learning Management System (LMS) such as BlackBoard provided by the university. As pictured, a range of Web 2.0 tools are being used to mediate activities that may require collaborative tasks or social communication with external communities. Teachers are able to keep the learning process on track with constant interaction and control over the LMS. Various shapes in the web cloud represent different kinds of Web 2.0 applications which are available to be used to support parts of learning activities. In this scenario, the two key players highlighted are the teacher and the students, surrounded by additional factors influencing a higher education teaching and learning settings.

The figure briefly describes the interrelation among various entities within the context of e-learning 2.0 and how each component works with each other for a complete learning to take place. It also describes the level of learning complexities that needs to tackle one at a time, which involve investigation on multiple entities including the students, teachers, and various other factors that are influencing one another in a Web 2.0 learning environment.

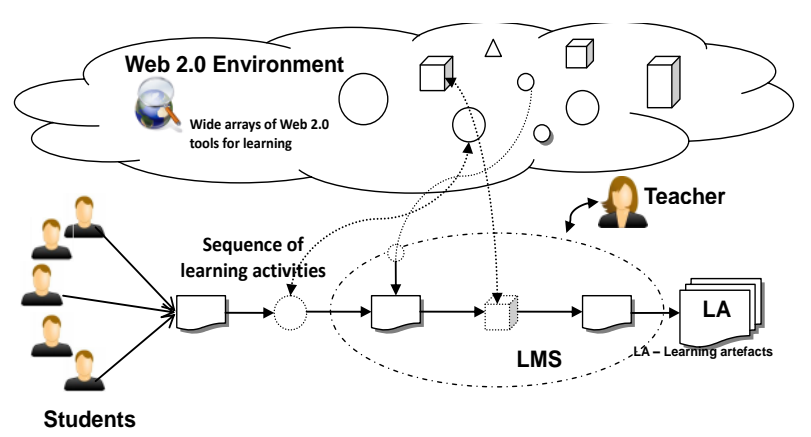

Fig. 1. Conceptual representation of e-learning 2.0 concept in higher education.

For each of those, we dealt with multiple sources of interaction and data rich information. What has been understood so far about the adoption of Web 2.0 tools in teaching and learning has been largely contributed by studies that used minimum set of data triangulation. Small scale studies could limit the richness of the results and confine the elaboration of phenomena due to the restrictions in data sources. By using mixed methods approach, we believe to be able to better articulate the issues surrounding these adoption areas. This was done by breaking down the entities identified in Figure 1 and appropriated relevant methods to address each entities individually.

\section{UsE OF MiXed MEthods RESEARCH}

The use of mixed methods as a research design involves mixing both qualitative and quantitative methods of data collection and analysis in a single study. In the past, a range of mixed methods and combined research approaches were adopted by researchers to enable the acquisition of data that would help to understand their research [14], [15]. The complementary nature of this approach can help to map out, or explain more fully, the richness and complexity of a context, by studying it from more than one standpoint. The adoption of mixed methods normally relies on the creativity of the researcher in developing new or adapting existing approaches such as triangulation to mix the data. From the educational disciplines, this approach is becoming widely accepted to answer multiple dimensions in a learning environment [16] in which single method studies are insufficient to describe some learning phenomena.

With such understanding in mind, a range of mixed methods data collection techniques were performed to uncover the complexities of the current e-learning 2.0 scenario on teachers and students respectively. For example, a series of methods were conducted to understand how students were using Web 2.0 tools to learn. For this, a quantitative survey followed by a qualitative observation was performed to analyze how they use and experience Web 2.0 in learning. Likewise, analysis of media messages and field study were done sequentially to understand the teachers' adoptions of Web 2.0 in classrooms. The convergence between the two methods was done in order to gain insights into the assumptions that can later help us to shape a deeper understanding. Also, across methods analysis were used for cross validation with aims to yield better accuracy of results. For instance, the findings about web 2.0 learning barriers found in students' reflective portfolio were compared with the results generated from the first quantitative survey about their motivation to uptake such learning approach. This event not only have provided us with a better view about the students engagement in web 2.0 learning but also assist with validating the accuracy of the methods selected and compensating the limitation of a single method.

Most of the data is textual - consisting of interview transcripts, observation notes (field study and researcher's diary), reflective documents and open ended survey questions. Influenced by Miles \& Huberman's analysis technique [17], this data is focused on records of naturally occurring, ordinary events in natural settings, so that researchers have a strong handle on what "real life" is like. Quantitative data, on the other hand, was retrieved from scores and counts generated from the surveys and content analysis of e-learning 2.0 relevant online discussions. This type of data would assist with the formulation of 
understanding by providing numerical evidence using scientific, precise and replicable steps which later help to minimize our subjectivity of qualitative interpretation.

Thus, the mixed method strategy was employed to provide a fuller description of cases in areas identified during the interviews, surveys or the literature review. The decision to use every instrument was influenced by the reasoning developed from the data collected in another study. The combination with other methods can be implemented concurrently to inform one another to generate breath of depth; or for the purpose of complementary - as a development bridge between the explorations of an inference. For instance, results gathered from the quantitative students survey not only informed the development of content analysis codebook but also provided insights on the construction of the teachers' semi structured interview questions. This also concurs with other mixed methods scholars about the results of using one kind of data collection techniques can inform or guide the use of another kind.

\section{A. Methods}

During the implementation of mixed methods study, a range of inter-connected data collections were done which allow the results to be triangulated to generate the understanding on how students and teachers use Web 2.0 in learning. The general idea is simplified in Figure 2.

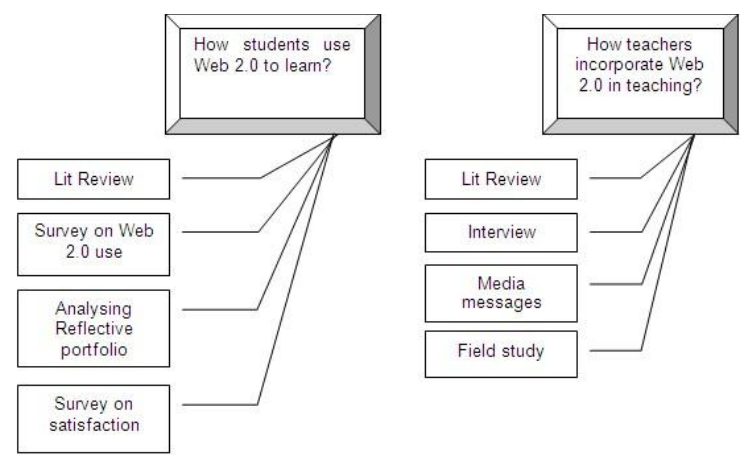

Fig. 2. List of methods undertaken to investigate students and teachers.

To understand how students use Web 2.0 to learn, we have used the literature review, two surveys, and a reflective portfolio. First, the literature was thoroughly reviewed to understand the way students make use and adopt Web 2.0 in general. Using that understanding, theirs familiarity and use of Web 2.0 for learning is later being investigated using survey. This survey adopted from previously used instrument also measures the level of involvement with a variety of web 2.0 tools and how much they use such tools on their daily activities. Following this, student's performance and their learning interaction were being investigated using their reflective portfolios that summarized their involvement in learning using Web 2.0 tools. Two learning units over the duration of two semesters were selected to enroll respondents for this type of method. To supplement the understanding, a field study technique was adopted by the researcher as the learning instructor. In this type of approach, any useful events happening during the learning interaction and Web 2.0 adoption by student was recorded. Finally, at the end of the units, surveys with open ended question were distributed to measure the students overall satisfaction on this type of learning approach and to invite the feedback on how this type of learning approach can be made better. By, gathering and analyzing all these information, a summary of Web 2.0 adoption by students is drawn.

Meanwhile for teachers, the data collections are being conducted to investigate the use of Web 2.0 in their teaching practices. The methods were undertaken in steps, parallel to the data collection processes performed on students. First, literature review was done to understand the range of Web 2.0 applications adopted by teachers in the classroom. Following this, interviews with seven teachers experienced with Web 2.0 integration was conducted to understand how Web 2.0 applications were being assimilated into the curriculum design and also to highlight what have been their experience with such integration. The teachers we interviewed represent a different group of teachers with different involvement of Web 2.0 implementation in learning. To complement the data obtained from the interview, a content analysis was performed on an online forum that discussed about issues surrounding the implementation of e-learning 2.0. More than 6000 discussions were filtered, analyzed and summarized with this regard. Finally, the experience of the researcher as the teaching instructor in Web 2.0 units was used as a field study. Week by week experience is being noted in the form of a researcher's diary, recording important events that can describe any challenges and issues faced by teachers when performing the Web 2.0 integration in learning. All these information will be used to describe the issues in Web 2.0 adoption by teachers.

At the end of both students and teachers data collection processes, the results were blended together. The main purpose is to strengthen both qualitative and quantitative analysis by combining insights from both techniques; and also to increase the credibility and validity of the results. This approach according to mixed methods scholar can assist researcher to provide a "more holistic, more nuanced, and more synergistic picture" of the research endeavor than has previously been possible [18].

\section{DISCUSSION}

This section describes the connectivity between the mixtures of methods that we have used and how the results obtained from one data collection is potentially useful to inform and validate other techniques. The details for the findings will be elaborated in other publication as the focus of this paper is to underline our research strategies on using mixed methods approach.

Using the triangulation of results, we identified various issues contributing towards the adoption of e-learning 2.0 by students. The literature review has provided us with fundamental insights of what other researchers have achieved with regard to the implementation of Web 2.0 in learning. The use of survey at the beginning of this study has furnished us with the level of Web 2.0 literacy among students and how they would likely to react and use the tools for learning. When combined with the analysis on the students learning portfolio has supplied us with a new level of data richness about the way learning has been undertaken 
while unlocking other issues related to students' motivations, feelings and expectations. Meanwhile, the strategy with the final survey was to validate some of the findings from earlier analysis and quantitatively ranked the impact of issues we identified previously.

Reflecting the sequence of multiple data collection enquiries performed on students, we adopted the similar approach on teachers. The literature we reviewed has covered many articles relevant to the e-learning 2.0 context including white papers, reports, conference proceedings and journal articles including blog entries by learning professionals. Some findings gathered from the literature have provided us with a general understanding about the current trend of what is happening in Web 2.0 learning among teachers as well as supplying us with a conceptual framework for the construction of semi-structured interview questions. Using prior results from the literature has helped us to better understand the Web 2.0 learning context which later contributed to the development of other data collection techniques. For instance, the interview results have not only simulated the adoption of Web 2.0 in the classrooms by the teachers, but they have also validated some of the findings gathered from the literature. Bringing it further, they later fed into the construction of codebook to analyze contents in the online forum.

The risk involves with this method however lies on the accuracy of methods used to collect data. Problems may arise if methods are mixed without careful consideration of the particular assumptions and expectations regarding their conduct. Corruption of those methods can occur whereby results obtained by them could subject to question [19]. To minimize the risk, researchers are encouraged to perform a thorough review on types of data that would yield the maximum impact on the unit of study they attempted to address. Also methods need to be appropriated with the time limit a researcher would have as normally this kind of approach would demand a great deal of time from the researcher to acquire sufficient amount of data and to deal with the analysis at a later stage.

This overview paper does not assume to provide definitive understanding of the current Web 2.0 phenomena in learning but it is expected to uncover multifaceted issues that emerged from diverse data collection technique. Later by conducting further analysis, it is expected that the mixed method technique we adopted can reveal practical practices for designing learning using Web 2.0 tools to improve collaboration and better engaged current students to enhance their learning experience.

\section{CONCLUSION}

The mixed methods approach has allowed a balanced review of web 2.0 adoptions by both the students and teachers in higher education learning context. Using both perspectives, our next task is to bridge the gap of differences and propose a counter balance measures so that the effectiveness of e-learning 2.0 integration can be achieved. The methods have also add depth to our understanding on a particular problem and perhaps even unlock the key to other issues which could potentially hidden beneath the results analyzed using a single method approach.
So far the results we gathered from this approach are very rich and multilayered, demanding a comprehensive analysis to be done. Some of the early findings have revealed that Web 2.0 may not be necessarily the total solution for learning in the digital age. We found that the implementations across institutions have reached to a significant level although the level of actual e-learning 2.0 implementation by teachers would vary according to the subject matter and their methods of learning delivery. In many instances, traditional lecture style approaches are still being widely preferred and adopted. This also indicates that learning using Web 2.0 is not a 'silver bullet' that can provide the total solution for enhancing learning for current student. Rather, it has afforded a platform where learning can be personalized to a greater extent while providing more rooms for teachers and students to foster communication and collaboration.

Overseeing so many variations, it is still acceptable to conclude at this stage that Web 2.0 applications have already being accepted by students and teachers as another learning alternative that is capable to enhance their learning experiences. Looking at the wide affordances that Web 2.0 can offer, many scholars believe that e-learning 2.0 concept will work well in educational practice and provide good opportunities to assist in learning collaboration and cocreation of knowledge in many years to come. This will continue to send signals for more researchers to carry further work in this field.

\section{REFERENCES}

[1] M. Ebner, "E-Learning 2.0 = e-Learning $1.0+$ Web 2.0?" in Proc ARES 2007 - The Second International Conference on Availability, Reliability and Security, pp 1235-1239, 2007.

[2] T. Franklin and M. V. Harmelen, "Web 2.0 for Content for Learning and Teaching in Higher Education," JISC: Joint Information Systems Committee, UK. pp.27, 2007.

[3] H. Ajjan and R. Hartshorne, "Investigating faculty decisions to adopt Web 2.0 technologies: Theory and empirical tests," The Internet and Higher Education, vol.11, no. 2, pp.71-80, 2008.

[4] M. Liu, D. Kalk, L. Kinney, G. Orr, and M. Reid, "Web 2.0 and Its Use in Higher Education: A Review of Literature," in: Bastiaens T, Dron J, and Xin C, editors. World Conference on E-Learning in Corporate, Government, Healthcare, and Higher Education 2009. Vancouver, Canada: AACE. pp. 2871-2880, 2009.

[5] J. B. Caruso and R. B. Kvavik RB, "Students and Information Technology, 2005: Convenience, Connection, Control, and Learning," ECAR: Educause Center for Applied Research. Washington DC: EDUCAUSE, 2005.

[6] G. E. Kennedy, B. Dalgarno, K. Gray, T. Judd, J. Waycott, S. Bennett, K. Maton, K. L. Krause, A. Bishop, and R. Chang, "The net generation are not big users of Web 2.0 technologies: Preliminary findings," In: Atkinson R, Mcbeath C, Kit ASS, and Cheers C, (Ed). ASCILITE 2007. Singapore, pp. 517-525, 2007.

[7] J. B. Caruso and G. Salaway, "The ECAR Study of Undergraduate Students and Information Technology, 2008," ECAR Research Studies Colorado: EDUCAUSE Center for Applied Research, 2008.

[8] G. E. Kennedy, T. S. Judd, A. Churchward, K. Gray, and K.L Krause, "First year students' experiences with technology: Are they really digital natives," Australasian Journal of Educational Technology, vol. 24, no. 1, pp. 108-122, 2008.

[9] M. H. Zakaria, J. Watson, and S. L. Edwards, "New Learning Affordances for New Learners: A Preliminary Review on the Application of Web 2.0 in Education," Presented at the International Conference of Educational Research and Practice. Putrajaya, Malaysia, 2009.

[10] C. Greenhow, B. Robelia, and J. E. Hughes, "Learning, Teaching, and Scholarship in a Digital Age," Educational Researcher, vol. 38, no. 4, pp. 246-259, 2009 
[11] P. Sendall, W. Ceccucci, and A. R. Peslak, "Web 2.0 Matters: An Analysis of Implementing Web 2.0 in the Classroom," Information System Education Journal, vol. 6, no. 64, 2008.

[12] H. Rollett, M. Lux, M. Strohmaier, and G. Dosinger, "The Web 2.0 way of learning with technologies," International Journal of Learning Technology, vol. 3, no. 1, pp.87-107, 2007.

[13] C. Crook, J. Cummings, T. Fisher, R. Graber, C. Harrinson, C. Lewin, K. Logan, R. Luckin, M. Oliver, and M. Sharples. Web 2.0 technologies for learning at Key Stages 3 and 4. Coventry, BECTA, 2008.

[14] R. B. Johnson, A. J. Onwuegbuzie, and L. A. Turner, "Toward a Definition of Mixed Methods Research," Journal of Mixed Methods Research, vol. 1, no. 2, pp.112-133, 2007.
[15] A. J. Onwuegbuzie, and K. Collins, "A typology of mixed methods sampling designs in social science research," The Qualitative Report, vol. 12, no. 2, pp.281-316, 2007.

[16] J. W. Creswell and V. L. Plano Clark, Designing and Conducting Mixed Methods Research, Sage, Thousand Oaks, CAA, 2007.

[17] M. Miles and A. Huberman, Qualitative data analysis: An expanded sourcebook: SAGE publications, Inc., 1994.

[18] C. Day, P. Sammons and Q. Gu, "Combining Qualitative and Quantitative Methodologies in Research on Teachers' Lives, Work, and Effectiveness: From Integration to Synergy," Educational Researcher, vol. 37, no. 6, pp.330-342, 2008.

[19] P. Bazeley, "Issues in mixing qualitative and quantitative approaches to research," In J. G. L. R. R. Buber (Ed.), Applying qualitative methods to marketing management research. UK: Palgrave Macmillan. pp.141-156, 2004 